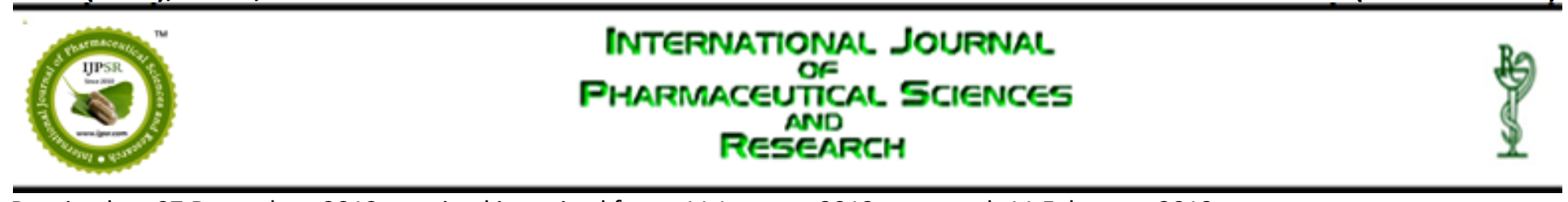

Received on 07 December, 2012; received in revised form, 11 January, 2013; accepted, 11 February, 2013

\title{
NOVEL DRUG DELIVERY SYSTEMS: AN OVERVIEW
}

\section{R.R. Bhagwat* and I.S. Vaidhya}

Department of Quality Assurance, Dr. L.H. Hiranandani College of Pharmacy, C.H.M. College Campus, Opp. Rly Stn., Ulhasnagar- 421003, Maharashtra, India

\section{Keywords:}

Drug release, Dosage forms, Novel drug delivery system, herbal formulations

Correspondence to Author:

\section{R.R. Bhagwat}

Department of Quality Assurance, Dr. L.H. Hiranandani College of Pharmacy, C.H.M. College Campus, Opp. Rly Stn., Ulhasnagar- 421003, Maharashtra, India

E-mail: rohita88@rediffmail.com

\begin{abstract}
Evolution of an existing drug molecule from a conventional form to a novel delivery system can significantly improve its performance in terms of patient compliance, safety and efficacy. In the form of a Novel Drug Delivery System an existing drug molecule can get a new life. An appropriately designed Novel Drug Delivery System can be a major advance for solving the problems related towards the release of the drug at specific site with specific rate. The need for delivering drugs to patients efficiently and with fewer side effects has prompted pharmaceutical companies to engage in the development of new drug delivery system. This article covers the basic information regarding Novel Drug Delivery Systems and also different types of the same.
\end{abstract}

INTRODUCTION: The method by which a drug is delivered can have a significant effect on its efficacy. Some drugs have an optimum concentration range within which maximum benefit is derived, and concentrations above or below this range can be toxic or produce no therapeutic benefit at all ${ }^{1}$. On the other hand, the very slow progress in the efficacy of the treatment of severe diseases, has suggested a growing need for a multidisciplinary approach to the delivery of therapeutics to targets in tissues.

From this, new ideas on controlling the pharmacokinetics, pharmacodynamics, non-specific toxicity, immunogenicity, biorecognition, and efficacy of drugs were generated. These new strategies, often called drug delivery systems (DDS), which are based on interdisciplinary approaches that combine polymer science, pharmaceutics, bioconjugate chemistry, and molecular biology. To minimize drug degradation and loss, to prevent harmful side-effects and to increase drug bioavailability and the fraction of the drug accumulated in the required zone, various drug delivery and drug targeting systems are currently under development ${ }^{1}$. Controlled and Novel Drug Delivery which was only a dream or at best a possibility is now a reality. During the last decade and half pharmaceutical and other scientists have carried out extensive and intensive investigations in this field of drug research.

Among drug carriers one can name soluble polymers, microparticles made of insoluble or biodegradable, natural and synthetic polymers, microcapsules, cells, cell ghosts, lipoproteins, liposomes, and micelles. The carriers can be made slowly degradable, stimulireactive (e.g., $\mathrm{pH}$ - or temperature-sensitive), and even targeted (e.g., by conjugating them with specific antibodies against certain characteristic components of the area of interest). Targeting is the ability to direct the drug-loaded system to the site of interest. Two major mechanisms can be distinguished for addressing the desired sites for drug release: 
(i) Passive and;

(ii) Active targeting ${ }^{1}$

An example of passive targeting is the preferential accumulation of chemotherapeutic agents in solid tumors as a result of the enhanced vascular permeability of tumor tissues compared with healthy tissue. A strategy that could allow active targeting involves the surface functionalization of drug carriers with ligands that are selectively recognized by receptors on the surface of the cells of interest. Since ligand-receptor interactions can be highly selective, this could allow a more precise targeting of the site of interest (see fig. 1)

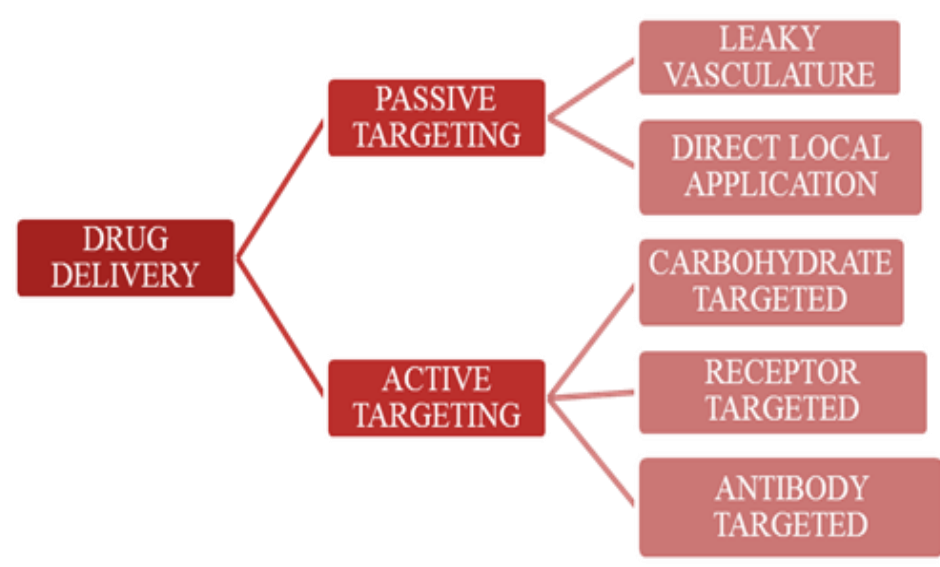

FIGURE 1: TYPES OF DRUG DELIVERY

Any drug delivery system may be defined as a system comprising of:

a) Drug formulation

b) Medical device or dosage form/technology to carry the drug inside the body

c) Mechanism for the release

Conventional drug delivery involves the formulation of the drug into a suitable form, such as a compressed tablet for oral administration or a solution for intravenous administration. These dosage forms have been found to have serious limitations in terms of higher dosage required, lower effectiveness, toxicity and adverse side effects. New drug delivery systems have been developed or are being developed to overcome the limitation of the conventional drug delivery systems to meet the need of the healthcare profession.
These systems can be characterised as controlled drug release systems and targeted drug delivery systems.

The therapeutic benefits of these new systems include:

- Increased efficacy of the drug

- Site specific delivery

- Decreased toxicity/side effects

- Increased convenience

- Viable treatments for previously incurable diseases

- Potential for prophylactic applications

- Better patient compliance.

There is no uniform and established definition of drug delivery systems. It is assumed to be based on two basic parameters:

Route of entry (A) and Dosage form (B).

Any member of the cartesian product of $(A X B)$ is defined as a drug delivery system.

Such a definition implies that there are a vast number of members in this group. Many of them may not even be feasible, while many others may not be relevant. So, the set of most relevant new drug delivery systems is deduced as follows:

Various Drug Delivery Systems:

\section{Carrier based Drug Delivery System:}

A) Liposomes

B) Nanoparticles

C) Microspheres

D) Monoclonal antibodies

E) Niosomes

F) Resealed erythrocytes as drug carriers

\section{Trasdermal Drug Delivery Systems:}

A) Sonophoresis

- Mucoadhesive delivery systems 
- Supramolecular delivery systems

- Variable release delivery systems

B) Osmotic pump

C) Microencapsulation

Drug Delivery Carriers: Colloidal drug carrier systems such as micellar solutions, vesicle and liquid crystal dispersions, as well as nanoparticle dispersions consisting of small particles of 10-400 nm diameter show great promise as drug delivery systems. When developing these formulations, the goal is to obtain systems with optimized drug loading and release properties, long shelf-life and low toxicity ${ }^{2}$. The incorporated drug participates in the microstructure of the system, and may even influence it due to molecular interactions, especially if the drug possesses amphiphilic and/or mesogenic properties (see fig. 2)

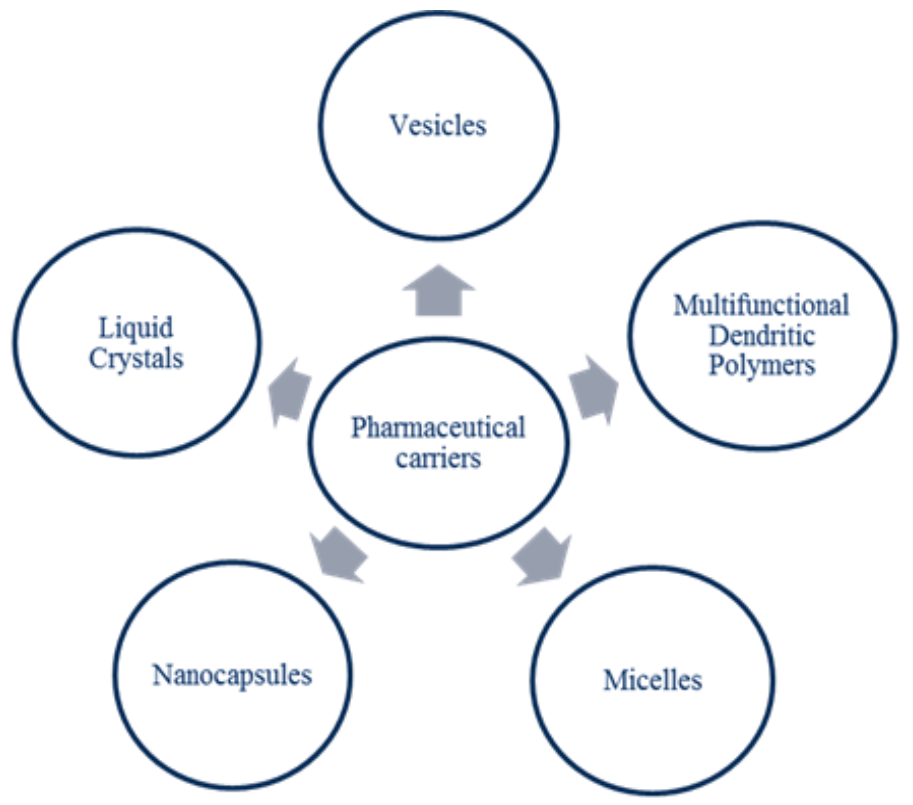

FIGURE 2: DIFFERENT PHARMACEUTICAL CARRIERS

Pharmaceutical Carriers: Micelles formed by selfassembly of amphiphilic block copolymers (5-50 nm) in aqueous solutions are of great interest for drug delivery applications. The drugs can be physically entrapped in the core of block copolymer micelles and transported at concentrations that can exceed their intrinsic water- solubility. Moreover, the hydrophilic blocks can form hydrogen bonds with the aqueous surroundings and form a tight shell around the micellar core. As a result, the contents of the hydrophobic core are effectively protected against hydrolysis and enzymatic degradation. In addition, the corona may prevent recognition by the reticuloendothelial system and therefore preliminary elimination of the micelles from the bloodstream.

A final feature that makes amphiphilic block copolymers attractive for drug delivery applications is the fact that their chemical composition, total molecular weight and block length ratios can be easily changed, which allows control of the size and morphology of the micelles. Functionalization of block copolymers with crosslinkable groups can increase the stability of the corresponding micelles and improve their temporal control. Substitution of block copolymer micelles with specific ligands is a very promising strategy to a broader range of sites of activity with a much higher selectivity ${ }^{3}$ (see fig. 3 ).

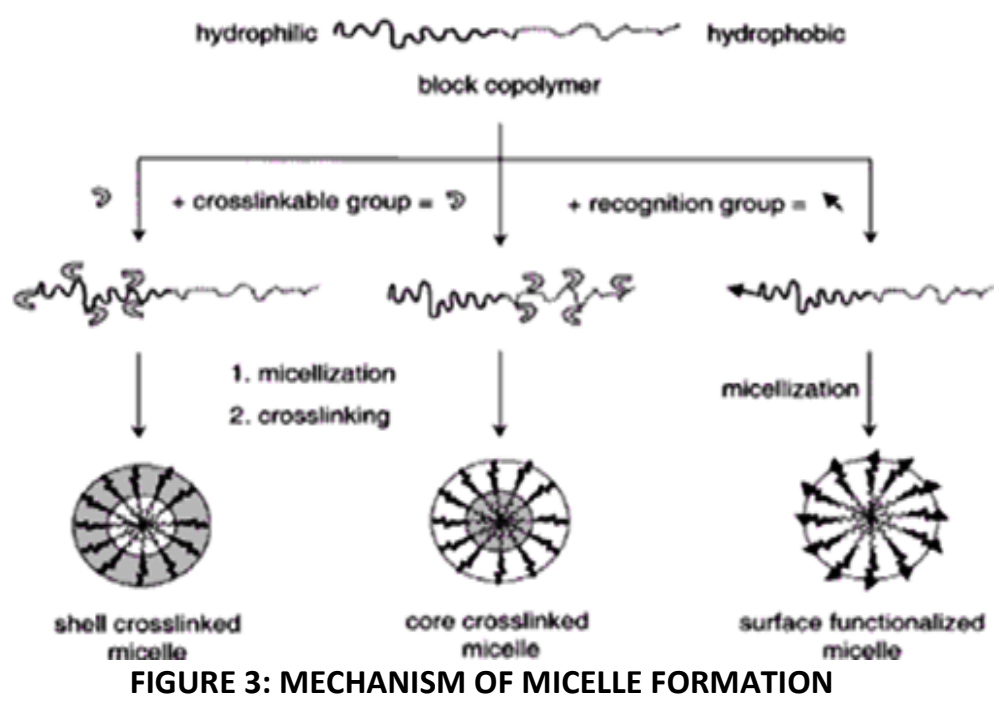

Liposomes: Liposomes are a form of vesicles that consist either of many, few or just one phospholipid bilayers. The polar character of the liposomal core enables polar drug molecules to be encapsulated. Amphiphilic and lipophilic molecules are solubilised within the phospholipid bilayer according to their affinity towards the phospholipids. Participation of nonionic surfactants instead of phospholipids in the bilayer formation results in niosomes. Channel proteins can be incorporated without loss of their activity within the hydrophobic domain of vesicle membranes, acting as a size-selective filter, only allowing passive diffusion of small solutes such as ions, nutrients and antibiotics.

Thus, drugs that are encapsulated in a nanocagefunctionalized with channel proteins are effectively protected from premature degradation by proteolytic enzymes. 
The drug molecule, however, is able to diffuse through

between the interior and the exterior of the nanocage 4 the channel, driven by the concentration difference (see fig. 4).
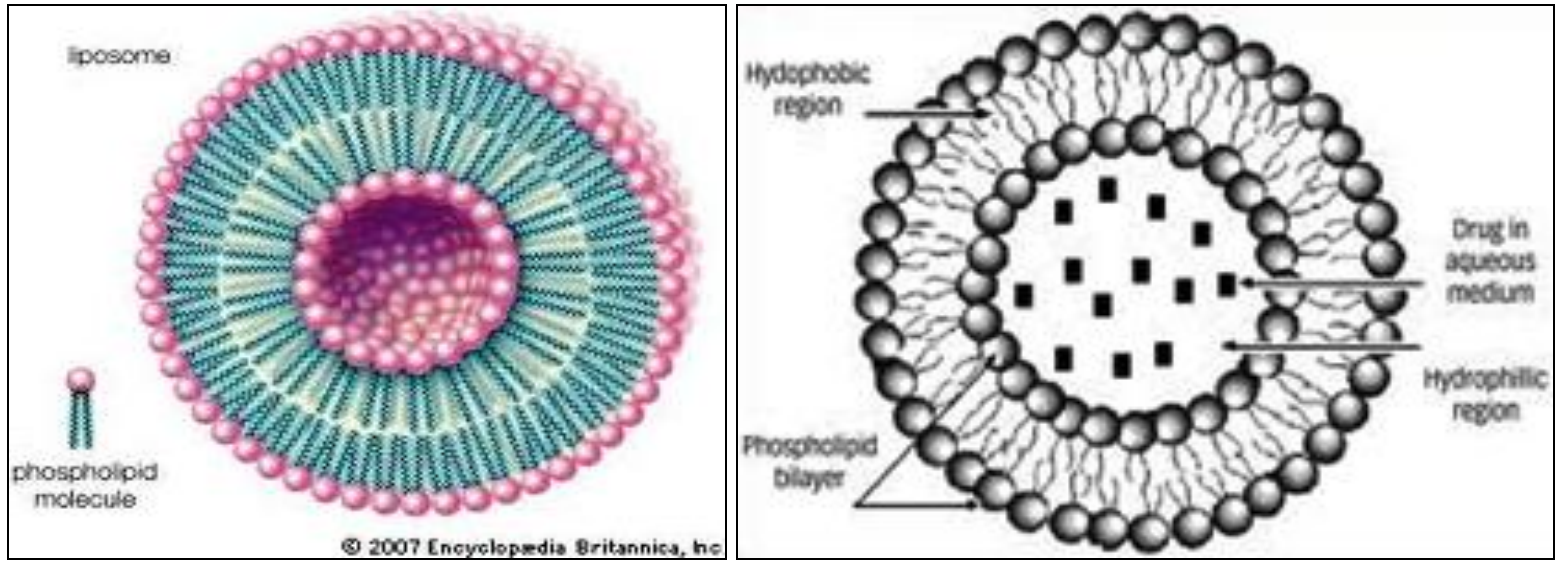

FIGURE 4: STRUCTURE OF LIPOSOME

Dendrimers are nanometer-sized, highly branched and monodisperse macromolecules with symmetrical architecture. They consist of a central core, branching units and terminal functional groups. The core together with the internal units, determine the environment of the nanocavities and consequently their solubilizing properties, whereas the external groups the solubility and chemical behaviour of these polymers. Targeting effectiveness is affected by attaching targeting ligands at the external surface of dendrimers, while their stability and protection from the Mononuclear Phagocyte System (MPS) is being achieved by functionalization of the dendrimers with polyethylene glycol chains (PEG). Liquid Crystals combine the properties of both liquid and solid states. They can be made to form different geometries, with alternative polar and non-polar layers (i.e., a lamellar phase) where aqueous drug solutions can be included.

TABLE 1: EXAMPLES OF PATENTS FOR LIPOSOMES

\begin{tabular}{|c|c|c|c|}
\hline Patent No & Assignee/Inventors & Filed On & Title \\
\hline US20100209492 $2^{[5]}$ & SDG,Inc, Cleveland,OH & January 14,2010 & Targeted Liposomal Drug Delivery System \\
\hline US20070286898 ${ }^{[6]}$ & Astellas Pharma Inc., Tokyo, JP & August 30,2005 & Intracellular Drug Delivery Improving Liposome \\
\hline US20070104777 $7^{[7]}$ & Lau; John R; et al. & December 21, 2006 & Targeted Liposomal Drug Delivery System \\
\hline US20070014845 & Zhang; Yuanpeng; et al. & June 30, 2006 & Liposomal Delivery Vehicle For Hydrophobic Drugs \\
\hline US20020182248 ${ }^{[9]}$ & Daiichi Pharmaceuticals Co. Ltd. & August 29, 2001 & Liposomes And Liposomal Dispersions \\
\hline
\end{tabular}

TABLE 2: SOME COMMERCIALLY AVAILABLE MARKETED LIPOSOMAL BASED PRODUCTS ${ }^{10}$

\begin{tabular}{ccccc}
\hline Trade Name & Trade Name & Manufacturer & Indication \\
\hline AmBisome & Amphotericin B & NeXstar Pharmaceuticals & Systemic fungal infections \\
Abelcet & Amphotericin B & The Liposome Company & Systemic fungal infections \\
Amphotec & Amphotericin B & Sequus Pharmaceuticals & Systemic fungal infections \\
Doxil & Doxorubicin & Sequus Pharmaceuticals & Kaposi's sarcoma \\
DaunoXome & Daunorubicin & NeXstar Pharmaceuticals & Kaposi's sarcoma \\
\hline
\end{tabular}

Nanoparticles: Nanoparticles (including nanospheres and nanocapsules of size 10-200nm) are in the solid state and are either amorphous or crystalline. They are able to adsorb and/or encapsulate a drug, thus protecting it against chemical and enzymatic degradation. In recent years, biodegradable polymeric nanoparticles have attracted considerable attention as potential drug delivery devices in view of their applications in the controlled release of drugs, in targeting particular organ/or tissue, as carriers of DNA in gene therapy, and in their abilities to deliver proteins peptides and genes through peroral route ${ }^{11}$.

\section{Classification of nanomaterials :}

A) Nanotubes- They are hallow cylinders made of carbon atoms. They can also be filled and sealed, forming test tubes or potential drug delivery devices. 
B) Nanowires- Glowing silica nano wire is wraped around a single stand of human hair. It looks delicate. It is about five times smaller than virus applications for nano wires include the early sensing of breast and ovarian malignancies.

C) Nanocantilever- The honey comb mesh behind this tiny carbon cantilever is surface of fly's eye. Cantilevers are beams anchored at only one end. In nano world they function as sensors ideal for detecting the presence of extremely small molecules in biological fluid.

D) Nanoshells- Nanoshells are hollow silica spheres covered with gold. Scientists can attach antibodies to their surfaces enabling the shells to target certain shells such as cancer cells. Nano shells one day also are filled with drug containing polymers.

E) Quantum dots- Quantum dots are miniscule semiconductor particles that can serve as sign pots of certain type of cells or molecules in the body. They can do this because they emit different wavelengths of radiations depending upon the type of cadmium used in their cores. Cadmium sulphide for ultraviolet to blue, cadmium selinide for most of the visible spectrum and cadmium telluride for far infra red and near infra red.

F) Nano pores- Nano pores have cancer research and treatment applications. Engineered into particles, they are holes that are so tiny that DNA molecules can pass through them one strand at a time allowing for highly precise and efficient DNA sequencing. By engineering nanopores into surface of drug capsule that are only slightly larger than medicines molecular structure, drug manufacturers can also use nanopores to control rate of drug's diffusion in body.

G) Gold nanoparticles- These nanoparticles seen in transmission electron micrograph image, they have solid core. Researchs at north western university are using gold particles to develop ultra sensitive detection systems for DNA and protein markers associated with many forms of cancer including breast, prostate cancer.
H) Bucky balls- Bucky ball is common for a molecule called buckminsterfullerene, which is made of 60 carbon atoms formed in shape of hollow ball discovered in 1985. Bucky balls and other fullerenes because of their chemistry and their unusual hollow cage like shape extremely stable and can withstand high temperatures.

Applications- Bucky balls may see widespread use in future products and applications, from drug delivery vehicles for cancer therapy to ultra hard coating and military harmor.

Bucky ball- Antibody combination delivers antitumor drugs.

- Bucky balls to fight allergy.

- Bucky balls as powerful antioxidants and also inhibitor of HIV.

Demerits:

- Bucky balls hurt cells.

- Bucky balls have high potential to accumulate in living tissue.

- Difficulty of targeting drug delivery location.

Carbon nanotubes: Carbon nanotubes can be modified to circulate well within the body. Such modifications can be accomplished with covalent or non covalent bonding. Modifications can increase or decrease circulation time within the body. Carbon nanotubes no significant toxicity when they have modified so as to be soluble in aqueous body type fluids. They enter readily into the cells.

Cancer cells in tumor are larger than normal cells and also exhibit leakage. Large molecules which circulate slowly can leak into and accumulate in cancer cell. Carbon nanotubes carrying active agents have been demonstrated in animal studies to do this. Researches have also used carbon tubes to deliver the precursors of active drug which they call a prodrug. eg: Cisplatin 12 
TABLE 3: EXAMPLES OF PATENTS FOR NANOPARTICLES

\begin{tabular}{|c|c|c|c|}
\hline Patent No & Assignee/Inventors & Filed On & Title \\
\hline US20100278920 ${ }^{13}$ & University of South Florida, Tampa, FL & April 26, 2010 & Polyacrylate Nanoparticle Drug Delivery \\
\hline US20090155374 ${ }^{14}$ & Sung; Hsing-Wen; et al. & January 15, 2009 & Nanoparticle For Protein Drug Delivery \\
\hline US20080095856 ${ }^{15}$ & Jacobson; Gunilla B; et al. & May 14, 2007 & Encapsulated Nanoparticle For Drug Delivery \\
\hline US20080145439 ${ }^{16}$ & Neurosystec Corporation, Valencia, CA & July 31, 2007 & Nanoparticle Drug Formulation \\
\hline
\end{tabular}

Microspheres: Microspheres are characteristically free flowing powders consisting of proteins or synthetic polymers which are biodegradable in nature and ideally having a particle size less than $200 \mu \mathrm{m}$. Materials used for preparing Microspheres are polymers. They are classified into two types:

1. Synthetic Polymers

2. Natural polymers

1. Synthetic polymers are divided into two types.

a. Non-biodegradable polymers

- Poly methyl methacrylate (PMMA)

- Glycidyl methacrylate

- Epoxy polymers

b. Biodegradable polymers

- Lactides, Glycolides \& their co polymers

- Poly alkyl cyano acrylates

- Poly anhydrides

Synthetic polymers: Poly alkyl cyano acrylates is a potential drug carrier for parenteral as well as other ophthalmic, oral preparations. Poly lactic acid is a suitable carrier for sustained release of narcotic antagonist, anti cancer agents such as cisplatin, cyclo phosphamide, and doxorubicin.

Sustained release preparations for anti malarial drug as well as for many other drugs have been formulated by using of co-polymer of poly lactic acid and poly glycolic acid. Poly anhydride microspheres $(40 \mu \mathrm{m})$ have been investigated to extend the precorneal residence time for ocular delivery.

Poly adipic anhydride is used to encapsulate timolol maleate for ocular delivery. Poly acrolein microspheres are functional type of microspheres. They do not require any activation step since the surfacial free $\mathrm{CHO}$ groups over the poly acrolein can react with $\mathrm{NH}_{2}$ group of protein to form Schiff's base.
In case of non-biodegradable drug carriers, when administered parenterally, the carrier remaining in the body after the drug is completely released poses possibility of carrier toxicity over a long period of time. Biodegradable carriers which degrade in the body to non-toxic degradation products do not pose the problem of carrier toxicity and are more suited for parenteral applications

2. Natural polymers obtained from different sources like proteins, carbohydrates and chemically modified carbohydrates.

Proteins: Albumin, Gelatin, and Collagen

Carbohydrates: Agarose, Carrageenan, Chitosan, Starch

Chemically modified carbohydrates: Polydextran, Poly starch.

Natural polymers: Albumin is a widely distributed natural protein. It is considered as a potential carrier of drug or protiens (for either their site specific localization or their local application into anatomical discrete sites). It is being widely used for the targeted drug for the targeted drug delivery to the tumour cells.

Gelatin microspheres can be used as efficient carrier system capable of delivering the drug or biological response modifiers such as interferon to phagocytes. Starch belongs to carbohydrate class. It consists of principle glucopyranose unit, which on hydrolysis yields D-glucose. It being a poly saccharide consists of a large number of free $\mathrm{OH}$ groups. By means of these free $\mathrm{OH}$ groups a large number of active ingredients can be incorporated within as well as active on surface of microspheres. Chitosan is a deacylated product of chitin. The effect of chitosan has been considered because of its charge. It is insoluble at neutral and alkaline $\mathrm{pH}$ values, but forms salts with inorganic and organic salts. Upon dissolution, the amino groups of chitosan get protonated, and the resultant polymer becomes positively charged ${ }^{17}$. 
TABLE 4: EXAMPLES OF PATENTS FOR MICROSPHERES

\begin{tabular}{cccc}
\hline Patent No & Assignee/Inventors & Filed On & Title \\
\hline US20110151004 & Wu; Daging; et al. & January 27, 2011 & $\begin{array}{c}\text { Injectable Microspheres } \\
\text { US20090318569 }\end{array}{ }^{[19]}$ \\
& S K Chemicals Co. LTD. Gyeonggi-di, KR & August 31, 2007 & $\begin{array}{c}\text { Method For Producing Microspheres } \\
\text { Loaded With Drugs \& Microspheres } \\
\text { Loaded With Drugs Produced Thereby }\end{array}$ \\
\hline
\end{tabular}

Resealed Erythrocytes as Drug Carriers: Erythrocytes, the most abundant cells in the human body, have potential carrier capabilities for the delivery of drugs. Erythrocytes are biocompatible, biodegradable, possess very long circulation half lives and can be loaded with a variety of chemically and biologically active compounds using various chemical and physical methods.

erythro $=$ red and cytes $=$ cell

Erythrocyte is red cell. Erythrocyte is biconcave discs, anucleate Filled with hemoglobin $(\mathrm{Hb})$, a protein that functions in gas transport. It contains the plasma protein spectrin.

Healthy adult male $=4.5$ millions $/ \mu \mathrm{ml}$

Healthy adult female $=4.8$ million $/ \mu \mathrm{ml}$

Immature RBC are called "RETICULOCYTES." [20]

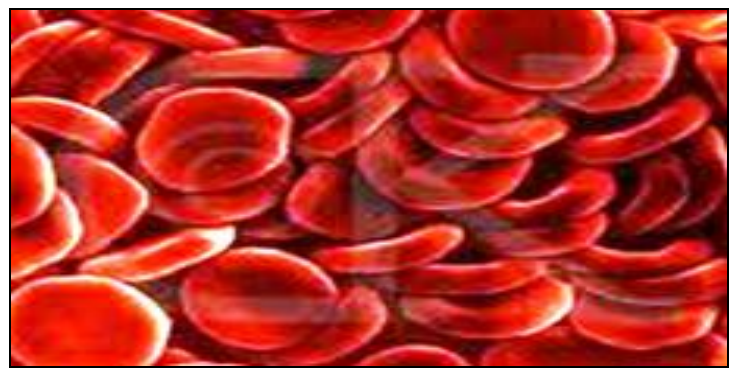

FIGURE 5: ERYTHROCYTES

Properties of resealed erythrocyte of novel drug delivery carriers:

1) The drug should be released at target site in a controlled manner.

2) It should be appropriate size, shape and should permit the passage through capillaries. And Minimum leakage of drug should take place.

3) It should be biocompatible and should have minimum toxic effect.

4) It should possess the ability to carry a broad spectrum of drug.
5) It should possess specific physicochemical properties by which desired target size could be recognized.

6) The degradation product of the carriers system , after release of the drug at the selected site should be biocompatible. It should be physico -chemically compatible with drug.

7) The carrier system should have an appreciable stability during storage.

\section{Advantage:}

1) They are natural part of body, so they are biodegradable in nature.

2) The entrapment of drug does not require the chemical modification of drugs

3) The entrapment of drug also does not require the chemical modification of the substance to be entrapped.

4) They are non immunogenic in action and can be targeted to disease tissue/organ..

5) They prolong the systemic activity of drug.

6) Isolation of erythrocyte is easy and larger amount of drug can be encapsulated in small volume of cells

7) They can target the drug within reticuloendothelial system.

8) They facilitate incorporation of protein and nucleic acid in eukaryotic cells by cell infusion with RBC.

\section{Disadvantage:-}

1) They have a limited potential as carrier to nonphagocyte target tissue.

2) Possibility of clumping of cells and dose dumping may be there ${ }^{21}$. 
Drug loaded Erythrocytes: This is one of the growing and potential systems for delivery of drugs and enzymes. Erythrocytes are biocompatible, biodegradable, posses long circulation half life and can be loaded with variety of biologically active substances. Carrier erythrocytes are preapared by collecting blood sample from the organism of interest and separating erythrocytes from the plasma. By using various physical and chemical methods cells are broken and drug is entrapped into erythrocytes, finally they are resealed and resultant carriers are then called as "resealed erythrocytes". Upon reinjection the drug loaded erythrocytes serve as slow circulation depots targets the drug to reticulo-endothelial system ${ }^{22}$.

\section{TABLE 5: EXAMPLES OF PATENTS FOR ERYTHROCYTE BASED DRUG DELIVERY}

\begin{tabular}{|c|c|c|c|}
\hline Patent No & Assignee/Inventors & Filed On & Title \\
\hline US20120141540 ${ }^{23}$ & Magnani; Mauro et al. & June 7,2010 & Drug Delivery System \\
\hline US20110262415 ${ }^{24}$ & Grimald; Settimio et al. & December 18,2009 & $\begin{array}{l}\text { Erythrocyte-based Delivery System method of preparation \& } \\
\text { uses thereof }\end{array}$ \\
\hline US20100284982 ${ }^{25}$ & Yang;Victor C. et al. & December 22, 2012 & $\begin{array}{l}\text { Erythrocyate-encapsulated L-asparginase For Enhanced Acute } \\
\qquad \text { Lymphoblastic Leukemia Therapy }\end{array}$ \\
\hline
\end{tabular}

Niosomes: In niosomes, the vesicles forming amphiphile is a non-ionic surfactant such as Span - 60 which is usually stabilized by addition of cholesterol and small amount of anionic surfactant such as dicetyl phosphate. Niosomes and liposomes are equiactive in drug delivery potential and both increase drug efficacy as compared with that of free drug. Niosomes are preferred over liposomes because the former exhibit high chemical stability and economy. Surfactant forming niosomes are biodegradable, nonimmunogenic and biocompatible. Incorporating them into niosomes enhances the efficacy of drug, such as nimesulide, flurbiprofen, piroxicam, ketoconazole and bleomycin exhibit more bioavailability than the free drug ${ }^{26}$.

Comparison of Niosomes and Liposomes: Niosomes are now widely studied as an alternative to liposomes, which exhibit certain disadvantages such as -they are expensive, their ingredients like phospholipids are chemically unstable because of their predisposition to oxidative degradation, they require special storage and handling and purity of natural phospholipids is variable. Niosomes are prepared from uncharged single-chain surfactant and cholesterol whereas liposomes are prepared from doublechain phospholipids (neutral or charged).

Niosomes behave in-vivo like liposomes, prolonging the circulation of entrapped drug and altering its organ distribution and metabolic stability. Encapsulation of various anti neoplastic agents in these carrier vesicles has been shown to decrease drug induced toxic side effects, while maintaining, or in some instances, increasing the anti-tumor efficacy. Such vesicular drug carrier systems alter the plasma clearance kinetics, tissue distribution, metabolism and cellular interaction of the drug. They can be expected to target the drug to its desired site of action and/or to control its release.

Various type of drug deliveries can be possible using niosomes like targeting, ophthalmic, topical, parentral.

TABLE 6: EXAMPLES OF PATENTS FOR NIOSOMAL DRUG DELIVERY

\begin{tabular}{cccc}
\hline Patent No & Assignee/Inventors & Filed On & Title \\
\hline US20100068264 & University of South Florida,Tampa,FL & November 20,2009 & Niosome Hydrogel Drug delivery Systems \\
\hline
\end{tabular}

Transdermal Drug Delivery System: Transdermal drug delivery is defined as self contained, discrete dosage forms which, when applied to the intact skin, deliver the drug, through the skin at controlled rate to the systemic circulation. Transdermal drug delivery system (TDDS) established itself as an integral part of novel drug delivery systems ${ }^{28}$. Delivery via the transdermal route is an interesting option because transdermal route is convenient and safe.
The positive features of delivery drugs across the skin to achieve systemic effects are:

- Avoidance of first pass metabolism

- Avoidance of gastro intestinal incompatibility

- Predictable and extended duration of activity

- Improving physiological and pharmacological response 
- Termination of therapy is easy at any point of time

- Greater patient compliance due to elimination of multiple dosing profile

- Provide suitability for self administration

- Enhance therapeutic efficacy

Sonophoresis is a process that exponentially increases the absorption of topical compounds (transdermal delivery) into the epidermis, dermis and skin appendages by ultrasonic energy. Sonophoresis is a localized, non-invasive, convenient and rapid method of delivering low molecular weight drugs as well as macromolecules into the skin. Mechanistically, sonophoresis is considered to enhance drug delivery through a combination of thermal, chemical and mechanical alterations within the skin tissue. Ultrasound at various frequencies in the range of 20 $\mathrm{kHz}-16 \mathrm{MHz}$ with intensities of up to $3 \mathrm{~W} / \mathrm{cm}^{2}$ has been used for sonophoresis. Ultrasound parameters such as treatment duration, intensity, and frequency are all known to affect percutaneous absorption, with the latter being the most important. Sonophoresis occurs because ultrasound waves stimulate micro-vibrations within the skin epidermis and increase the overall kinetic energy of molecules making up topical agents. The ultrasound probably enhances drug transport by cavitation, micro-streaming, and heating. Ultrasound mediated transdermal delivery of key compounds was first reported in 1954 by Fellinger and Schmid through successful treatment of digital polyarthritis using hydrocortisone ointment in combination with ultrasound. Sonophoresis is widely used in hospitals to deliver drugs through the skin. Pharmacists compound the drugs by mixing them with a coupling agent (gel, cream, ointment) that transfers ultrasonic energy from the ultrasound transducer to the skin. Thus, Application of ultrasound to the skin increases its permeability (sonophoresis) and enables the delivery of various substances into and through the the skin. Sonophoresis is also used in Physical Therapy. Reverse ultrasound technology may also be used for the extraction of interstitial fluid samples for analysis. So, In addition to its effects in delivering compounds into the skin, sonophoresis is being investigated as a way of drawing compounds such as glucose out of the skin ${ }^{29}$.

\section{TABLE 7: EXAMPLES OF PATENTS FOR TRANSDERMAL DRUG DELIVERY}

\begin{tabular}{|c|c|c|c|}
\hline Patent No & Assignee/Inventors & Filed On & Title \\
\hline US20110190716 $6^{30}$ & Easterbrook;Timothy J.et al. & June 2,2009 & Transdermal Drug Delivery Device \\
\hline US20110182949 31 & Tang; Jiashang & May 29,2009 & Stabilised Transdermal Drug Delivery System \\
\hline US20100222751 32 & Pharmapatch LLC San Diego, CA & September 22,2009 & Transdermal Drug Delivery Patch \\
\hline US20100143448 ${ }^{33}$ & $\begin{array}{c}\text { Koninklijke Philips Electronics } \\
\text { N.V., Eindhoven,NL }\end{array}$ & September 26,2007 & $\begin{array}{c}\text { Multiple Nozzle Transdermal Drug Delivery } \\
\text { System }\end{array}$ \\
\hline
\end{tabular}

TABLE 8: SOME COMMERCIALLY AVAILABLE MARKETED TRANSDERMAL SYSTEMS- ${ }^{[10]}$

\begin{tabular}{cccc}
\hline Product name & Chemical & Developer/Marketer & Indication \\
\hline Alora & Estradiol & TheraTech/Proctor and Gamble & Postmenopausal syndrome \\
Catapres-TTS & Clonidine & Alza/Boehinger Ingelheim & Hypertension \\
Deponit & Nitroglycerin & Schwarz-Pharma & Angina pectoris \\
Minitran & Nitroglycerin & $3 \mathrm{M}$ Pharmaceuticals & Angina pectoris \\
Transderm-Scop & Scopolamine & Alza/Novartis & Motion sickness \\
Motion sickness & Estradiol & Noven Pharmaceuticals, Inc./ Novartis & Postmenopausal syndrome \\
\hline
\end{tabular}

Mucoadhesive Drug Delivery Systems: Bioadhesion may be defined as the state in which two materials, at least one of which is biological in nature, are held together for extended period of time by interfacial forces. In pharmaceutical sciences, when the adhesive attachment is to mucus or a mucous membrane, the phenomenon is referred to as mucoadhesion.
The potential of mucoadhesive polymers was shown in ocular, nasal, vagina and buccal drug delivery systems leading to a significantly prolonged residence time of sustained release delivery systems on this mucosal membranes. In addition, the development of oral mucoadhesive delivery systems was always of great interest as delivery systems capable of adhering to certain gastrointestinal (GI) segments would offer various advantages ${ }^{34}$. 


\section{Mucoadhesive carrier}

Interaction with mucus

Hydration and swell of polymer

Drug release

Hydrophilic macromolecular drug

Cilliary clearance

Enzymatic metabolism

Internal absoption

FIGURE 6: MECHANISM OF MUCOADHESION
Supramolecular Drug Delivery Systems: A supramolecular system is composed of two or more molecular entities held together and organized by means of intermolecular non-covalent binding interactions. Supramolecular structures involving macrocyclic compounds have attracted tremendous interest not only as models for understanding natural supramolecular self-assembly and molecular recognition, but also as precursors for designing novel nanomaterials for electronics, biomedical and pharmaceutical applications ${ }^{35}$.

TABLE 9: EXAMPLES OF PATENTS FOR MUCOADHESIVE DRUG DELIVERY

\begin{tabular}{cccc}
\hline Patent No & Assignee/Inventor & Filed on & Title \\
\hline US20110028431 & Zerbe; Horst G; et al. & July 15,2010 & Oral Mucoadhesive Dosage Form \\
US20100100064 & Convatec technologies INC, Reno, NV & March 6,2008 & Ostomy Devices With mucoadhesives \\
US20090232899 & David; Allan E; et al. & May 20, 2005 & Mucoadhesive Nanocomposite Delivery System \\
\hline
\end{tabular}

\section{Osmotically Controlled Drug Delivery Systems:} Osmotic pressure is used as driving force for these systems to release the drug in controlled manner. Osmotic drug delivery technique is the most interesting and widely acceptable among all other technologies used for the same. Intensive research has been carried out on osmotic systems and several patents are also published. Development of osmotic drug delivery systems was pioneered by Alza and it holds major number of the patents analyzed and also markets several products based on osmotic principle. These systems can be used for both route of administration i.e. oral and parenterals. Oral osmotic systems are known as gastro-intestinal therapeutic systems (GITS). Parenteral osmotic drug delivery includes implantable pumps $^{39}$.

Classification of Osmotic Drug Delivery System: Many forms of osmotic pumps are reported in the literature but, in general they can be divided in oral and implantable systems.

Osmotic Drug Delivery Devices fall in two categories:

\section{- Implantable:}

- The Rose and Nelson Pump

- Higuchi Leeper Pump

- Higuchi Theuwes pump

- Implantable Miniosmotic pump

\section{- Oral osmotic Pump}

- Single chamber osmotic pump: Elementary osmotic pump

- Multi chamber osmotic pump: Push pull osmotic pump, Osmotic pump with non expanding second chamber

- Specific types: Controlled porosity osmotic pump, Osmotic bursting osmotic pump, Liquid OROS, Delayed Delivery Osmotic device, Telescopic capsule, Oros ct (colon targeting), Sandwiched oral therapeutic system, Osmotic pump for insoluble drugs, Monolithic osmotic system and OSMAT ${ }^{40}$.

Advantages: Osmotic drug delivery system for oral and parenteral use offer distinct and practical advantage over other means of delivery. The following advantages contributed to the popularity of osmotic drug delivery systems.

- They typically give a zero order release profile after an initial lag.

- Deliveries may be delayed or pulsed if desired.

- Drug release is independent of gastric $\mathrm{pH}$ and hydrodynamic condition.

- They are well characterized and understood. 
- The release mechanisms are not dependent on drug.

- A high degree of in-vitro and in-vivo correlation (ivivc) is obtained in osmotic systems.

- The rationale for this approach is that the presence of water in git is relatively constant, at least in terms of the amount required for activation and controlling osmotically base technologies.

- Higher release rates are possible with osmotic systems compared with conventional diffusioncontrolled drug delivery systems.

- The release from osmotic systems is minimally affected by the presence of food in gastrointestinal tract.
- The release rate of osmotic systems is highly predictable and can be programmed by modulating the release control parameters.

\section{Disadvantages:}

- Expensive

- If the coating process is not well controlled there is a risk of film defects, which results in dose dumping

- Size hole is critical

- Dose dumping

- Retrival therapy is not possible in the case of unexpected adverse events.

TABLE 10: EXAMPLES OF PATENTS FOR OSMOTIC DRUG DELIVERY SYSTEM

\begin{tabular}{|c|c|c|c|}
\hline Patent No & Assignee/Inventor & Filed On & Title \\
\hline US20090004281 & $\begin{array}{l}\text { Biovail Laboratories International S.R.L. St. } \\
\text { Michael, BB }\end{array}$ & June 26, 2007 & Multiparticulate Osmotic Delivery System \\
\hline US20080248114 ${ }^{42}$ & Reliant pharmaceuticals INC. Liberty corner, NJ & June 11, 2008 & Oral Osmotic Drug Delivery System \\
\hline US20070254032 43 & Kidane; Argaw; et al. & April 27, 2006 & Osmotic Drug Delivery System \\
\hline
\end{tabular}

TABLE 11: SOME COMMERCIALLY AVAILABLE MARKETED ORAL OSMOTIC SYSTEMS- ${ }^{[10]}$

\begin{tabular}{cccc}
\hline Product name & Chemical & Developer/Marketer & Indication \\
\hline Alpress LP & Prazosin & Alsa/Pfizer (France) & Hypertension \\
Calan SR & Verapamil & Alza/GD Searle \& Co. & Hypertension \\
Covera HS & Verapamil & Alza/G.D. searle & Hypertension \\
Efidac/24 & Pseudoephedrine & Alza/Novartis & Cold medication. \\
Glucotrol XL & Glipizide & Alza/Pfizer & Anti-diabetic \\
Minipress XL & Prazosin & Alza/Pfizer & Hypertension \\
Volmax & Albuterol & Alza/Muro Pharmaceuticals & Bronchospasm \\
\hline
\end{tabular}

Microencapsulation: Microencapsulation is the process in which small droplets or particles of liquid or solid material are surrounded or coated by a continuous film of polymeric materials. Firstly the microencapsulation procedure was discovered by Bungen burg de Jon and Kan in 1931 and which were deal with the preparation of gelatin spheres and use of a gelatin coacervation process.

The controlled drug delivery system has used to reduce the problems associated with conventional therapy and to improve the therapeutic efficacy of a given drug. The maximum therapeutic efficacy can be achieved by delivering of the active agent in the optimal rate to the target tissue, then causing little toxicity and minimum side effects.
Microencapsulation process helps for converting the liquids to solids, changing the colloidal and surface properties, providing environmental protection and controlling the release characteristics of different coated materials. Some of these properties can be achieved by macropakaging techniques but in microencapsulation the small coated particles are used to make a wide variety of dosage forms and has not been feasible.

Novel drug delivery systems which were initiate with the course of optimizing the bioavailability by the modification of the bioavailability of the drug concentration in blood. With the sustained and controlled release products, drug therapy can be improved that is the common goal achieved over with 
their non sustained and controlled release with the same drug. Microencapsulated products (micro particles) are the small entities that have an active agent know as the core material surrounded by a shell known as the coating material or embedded into a matrix structure. Most Microparticle shells are of organic polymers, but waxes and lipids are also used. Generally the size of the microencapsulated products (microparticles) is considered as larger than 1 micrometer and up to 1000 micrometers in diameter.

Commercially available microparticles contained 10$90 \% \mathrm{w} / \mathrm{w}$ core. A number of core materials can be encapsulated like that live cells, adhesives, flavors, agrochemicals, enzymes, pharmaceuticals. The more recent result of pharmaceutical research is that the absorption rate of a drug can be controlled by controlling its rate of release from the dosage form .The controlled released dosage forms are so designed and formulated as having the sustained action, sustained release, prolonged action, delayed action and timed release medication. This has been done by developing the new drug entities, discovering of new polymeric materials that are suitable for prolonging the drug release, safety, improvement in therapeutic efficacy ${ }^{44}$.

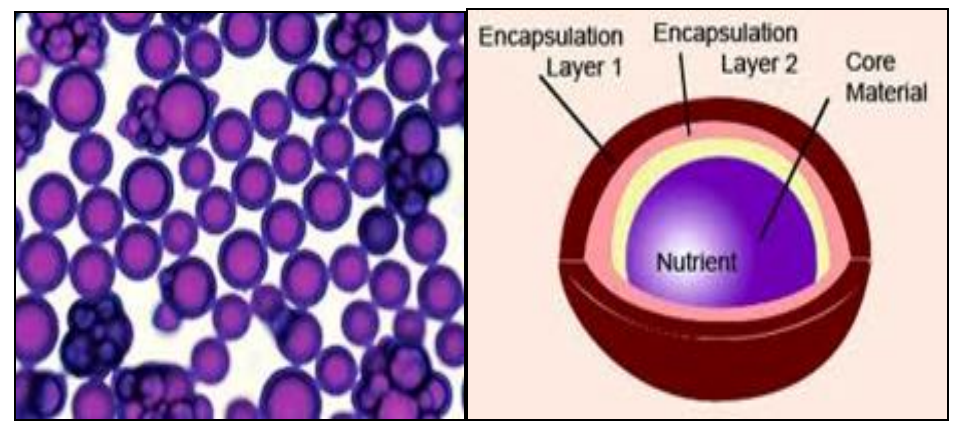

FIGURE 7: ENCAPSULATION

Novel Drug Delivery System: In Herbal Formulations: In the past few decades, considerable attention has been focused on the development of novel drug delivery system (NDDS) for herbal drugs. The novel carriers should ideally fulfill two prerequisites. Firstly, it should deliver the drug at a rate directed by the needs of the body, over the period of treatment. Secondly, it should channel the active entity of herbal drug to the site of action. Conventional dosage forms including prolonged-release dosage forms are unable to meet none of these.

The variety of novel herbal formulations like polymeric nanoparticles, nanocapsules, liposomes, phytosomes, nanoemulsions, microsphere, transferosomes, and ethosomes has been reported using bioactive and plant extracts ${ }^{45}$.

TABLE 12: EXAMPLES OF HERBAL NDDS FORMULATIONS

\begin{tabular}{|c|c|c|c|}
\hline FORMULATIONS & TYPE OF NDDS & APPLICATION & BIOLOGICAL ACTIVITY \\
\hline Ampelopsin Liposomes ${ }^{[46]}$ & Liposome & Increase efficiency & Anticancer \\
\hline Paclitaxel Liposomes ${ }^{[47]}$ & Liposome & High entrapment efficiency \& pH sensitive & Anticancer \\
\hline Colchicine Liposomes $^{[48]}$ & Liposome & Prolong drug release & Antigout \\
\hline Artemisinin Nanocapsules ${ }^{[49]}$ & Nanocapsule & Sustained drug release & Anticancer \\
\hline Ginkgo biloba Nanoparticles ${ }^{[50]}$ & Nanoparticles & Improve cerebral blood flow & Brain function activation \\
\hline Hawthorn Phytosomes ${ }^{[51]}$ & Phytosome & Increase therapeutic efficacy $\&$ absorption & Cardioprotective \\
\hline Quercetin Phytosomes ${ }^{[52]}$ & Phytosome & Better therapeutic efficacy & Antioxidant \\
\hline Zedory oil Microspheres ${ }^{[45]}$ & Microsphere & Sustained release $\&$ higher bioavailability & Hepatoprotective \\
\hline
\end{tabular}

\section{Market Opportunities of Sustained Release Dosage}

Forms: The global market for advanced drug delivery systems amounted to $\$ 134.3$ billion in 2008 , and was projected to increase to $\$ 139$ billion in 2009 . The estimate for 2014 is $\$ 196.4$ billion, for a compound annual growth rate (CAGR) of $7.2 \%$ in the 5 -year period. The largest segment of the market is targeted drug delivery, which reached $\$ 50.9$ billion in 2009 and is expected to increase to $\$ 80.2$ billion in 2014, for a CAGR of $9.5 \%$.Sustained-release products have the second-largest market share, with estimated sales of \$36.1 billion in 2009 and $\$ 45.8$ billion in 2014, for a
CAGR of $4.9 \%$. Benefits for short half-life drugs, sustained release can mean less frequent dosing and thus better compliance reduce variations in plasma/blood levels for more consistent result ${ }^{53}$.

\section{REFERENCES :}

1. Reddy. P.D., Swarnalatha D.Recent advances in Novel Drug Delivery Systems. IJPTR, 2010; 2(3): 2025-2027.

2. Muller.C.C. "Physicochemical characterization of colloidal drug delivery systems such as reverse micelles, vesicles, liquid crystals and nanoparticles for topical administration", European Journal of Pharmaceutics and Biopharmaceutics. 2004; 58(2): 343-356.

3. http://www.azonano.com/oars.asp

4. Sharma A. International Journal of Pharmaceutics. 1997;154; 123-140. 
5. Lau JR, Geho WB, Snedekar GH, Inventors; SDG INC, An Ohio Corporation, Assignee; Targeted Liposomal Drug Delivery System. US Patent 20100209492. 2010 Aug 19.

6. Takagi A, Yamashita N, Sonobe T,Inventors; Astellas Pharma INC Tokyo, Assignee; Intracellular Drug Delivery Improving Liposomes. US Patent 20070286898. 2007 Dec 13.

7. Lau JR,Geho WB, Snedekar GH, Inventors; Targeted Liposomal Drug Delivery System. US Patent 20070104777. 2007 May 10.

8. Zhang Y, Luo B, Iyer L, Inventors; Liposomal Delivery Vehicle For Hydrophobic Drugs. US Patent 20070014845. 2007 Jan 18.

9. Yamauchi $\mathrm{H}$, Morita $\mathrm{H}$, Kikuchi $\mathrm{H}$, Inventors; Daiichi pharmaceuticals Co.LTD, Assignee; Liposomes And Liposomal Dispersion. US Patent 20020182248. 2002 Dec 5.

10. Rajan K. Verma and Sanjay Garg, "Current Status of Drug Delivery Technologies and Future Directions, Pharmacutical Technology On-Line, 25 (2), 1-14 (2001).

11. Aminabhavi T.M. JCR. 2001; 70; 1-20

12. Manivannan R. Recent Advances In Novel Drug Delivery System. IJRAP. 2010; 1(2); 316-326

13. Turos E, Cormier R, Kyle DE, Inventors; University of South Florida FL, Assignee; Polyacrylate Nanoparticle Drug Delivery. US Patent 20100278920. 2010 Nov 4.

14. Sung $\mathrm{H}$, liang $\mathrm{H}, \mathrm{Tu} \mathrm{H}$, Inventors; Nanoparticle For Protein Drug Delivery. US Patent 20090155374. 2009 June 18.

15. Jacobson GB, Zare RN, Markides KE, Shinde RR, Inventors; Encasulated Nanoparticle For Drug Delivery. US Patent 20080095856. 2008 Apr 24.

16. Lobl TJ, Schloss JV, Nagy AI, Pananen JE, Inventors; Neurosystec corporation, Valencia CA, Assignee; Nanoparticle Drug Formulation. US Patent 20080145439. 2008 June 19.

17. O'Neil, Jacklyn, "Controlling drug delivery for the application of extended or sustained-release drug products for parenteral administration". Chemistry Master's Theses. 2010; Paper 14.

18. Wu D, Chu CC, Carozza J, Inventors. Injectable Microspheres. US Patent 20110151004. 2011 June 23.

19. Sah HK, Inventor; SK Chemicals CO LTD KR, Assignee; Method For Producing Microspheres Loaded with Drugs And Microspheres Loaded With Drugs Produced Thereby. US Patent 20090318569. 2009 Dec 24.

20. Shah S. Novel Drug Delivery carrier:Resealed Erythrocytes. IJPBS. 2011; 2(1); 395-406.

21. Sahoo C.K. An overview on resealed erythrocytes:Anovel approach to drug delivery. IJPPS. 2012; 4(2);

22. Gupta A. Cell based drug delivery system through resealed erythrocyteA review. IJPSDR. 2010; 2(1); 23-30.

23. Magnani M, Rossi L, Biagiotti S, Bioanchi M, Inventors; Drug Delivery System. US Patent 20120141540. 2012 June 7.

24. Grimald S, Lisi A, Cinti C, Inventors; CNR Conciglio Nazionale Delle Ricerche Roma, Assignee; US Patent 20110262415. 2011 Oct 27.

25. Yang VC, Kwon YM, Chung HS, Yang AJ, Inventors; Erythrocyte encapsulated L- aspaginase for enhanced acute Lymphoblastic Leukemia Therapy. US Patent 20100284982. 2010 Nov 11.

26. Madhar NVS, Saini A. Niosomes: A novel drug delivery system. IJRPC. 2011; 1(3); 498-511.

27. Alcantor N, Williams EC, Toomey R, Inventors; University of South florida,FL, Assignee; Niosome Hydrogel Drug Delivery Systems. US Patemt 20100068264. 2010 Mar 18.

28. Arunachalam A., karthikeyan M., Vinay Kumar D. et al. Transdermal Drug Delivery System:A Review. Current Pharma Research. 2010; 1(1); 70-81.

29. Sharma B.,Saroha K., Yadav B. Sonophoresis: An advanced tool in transdermal drug delivery system. IJCPR. 2011; 3(3); 89-97.
30. Easterbrook TJ, Gosden E, Meyer E,Inventors; Transdermal Drug Delivery device. US Patent 20110190716. 2011 Aug 4.

31. Tang J.Inventor; Stabilised Transdermal Drug Delivery System. US Patent 20110182949. 2011 July 28.

32. Nisato G Baret JC,Inventors; Koninklijke Philips Electronics N.V, NC, Assignee; Transdermal Drug Delivery Patch. US Patent 20100222751. 2010 June 10.

33. 33. Heiati H, Weimann L, Inventor; Pharmapatch LLC, San Diego,CA,Assignee;Multiple Nozzle Transdermal Drug Delivery System. US Patent 20100143448. 2010 Sept 2.

34. \Vinod KR., Reddy R., Banji D., Reddy V., Sandhya S. Critical review on mucoadhesive drug delivery systems. Hygeia journal for drugs and medicines. 2012; 6(1); 7-28.

35. Hee Jae yoon, Woo Dong Jang. Polymeric supramolecular systems for drug delivery. JMC. 2010; 2; 211-222.

36. Zerbe HG, Paiement N, Inventor; Oral Mucoadhesive Dosage form. US Patent 20110028431. 2011 Feb 3.

37. Sambasivam M, Inventor; Convatec Technologies INC, NV, Assignee; Ostomy Devices With Mucoadhesives. US Patent 2010010064. 2010 Apr 22.

38. David $A E$, Zhang $R$, Park YJ, Yang AJM, Yang VC, Inventors; Mucoadhesive Vescicles For Drug Delivery. US Patent 20090232899. 2009 Sept 17.

39. Gupta S., Singh R.P., Sharma R., Kalyanwat R., Lokwani P. Osmotic pumps: A Review. IJCP. 2011; 6(1); 1-8.

40. Patel H., Patel U., Kadikar H., Bhimani B., Daslaniya D., Patel G. A review on osmotic drug delivery system. IRJP. 2012; 3(4); 88-94.

41. Nghiem T, Jackson G,Inventors; Biovail Laboratories International S.R.L., Assignee; Multiparticulate Osmotic Delivery System. US Patent 20090004281. 2009 Jan 1.

42. Patel HB, Inventor; Reliant pharmaceuticals INC., Assignee; Oral Osmotic Drug Delivery System. US Patent 20080248114. 2008 Oct 9.

43. Kidane A, Bhatt PP, Inventors; Osmotic Drug Delivery System. US Patent 20070254032. 2007 Nov 1.

44. Kumar A., Sharma P., Banik A. Microencapsulation as novel drug delivery system. Internationale Pharmaceutica Sciencia. 2011; 1(1); 1-7.

45. Saraf A.S. Applications of novel drug delivery system for herbal formulations. Fitoterapia. 2010;81;680-689.

46. He ZF, Liu DY, Zeng S, Ye JT. Study on preparation of ampelopsin liposomes. Journal Chine Mat Med. 2008; 33(1); 27-30.

47. Rane S, Prabhakar B. Influence of liposome composition on paclitaxel entrapment \& pH sensitivity of liposomes. IJPTR.2009; 1(3); 914-917.

48. Godin B., Touitou E. Mechanism of bacitricin permeation enhancement through the skin \& cellular membrane from an ethosomal carrier. Journal of Control Release. 2004; 94(2-3); 365-379.

49. Youfang C., Xianfu L., Hyunjin P., Richard G. Artemisnin nanoparticles. Nanomed Nanotechnol Biol Med. 2009; 5; 316-322.

50. Shimada S. Composition comprising nanoparticle Ginkgo biloba extract with the effect of brain function activation. US Patent 8105637; 2012 Jan 31.

51. Bhattacharya S. Phytosomes: Emerging strategy in delivery of herbal drugs \& nutraceuticals. Pharma Times. 2009; 41(3); 9-12.

52. Jzu-Hui Wu,Feng-Lin Yen, Liang-Tzung Lin, Tong-Rong Tsai, Chun-Ching Lin et al. Preparation, physicochemical characterization \& antioxidant effects of quercetin nanoparticle. IJP. 2008; 346; 160-168.

53. Sampath Kumar K.P., Bhowmik D., Chiranjib., Chandira M., Tripathi K.K. Innovations in Sustained Release Drug Delivery System and Its Market Opportunities. J. Chem. Pharm. Res., 2010; 2(1); 349-360.

How to cite this article:

Bhagwat RR and Vaidhya IS: Novel Drug Delivery Systems: An Overview. Int J Pharm Sci Res. 2013; 4(3); 970-982. 